\title{
SCIENCE AND RELIGION
}

\section{one world - changing perspectives on reality}

Papers presented at the

Second European Conference on Science and Religion March 10-13, 1988

University of Twente

edited by

Jan Fennema and Iain Paul

KLUWER ACADEMIC PUBLISHERS DORDRECHT / BOSTON / LONDON 
Published by Kluwer Academic Publishers,

P.O. Box 17, 3300 AA Dordrecht, The Netherlands.

Kluwer Academic Publishers incorporates the publishing programmes of

D. Reidel, Martinus Nijhoff, Dr W. Junk and MTP Press.

Sold and distributed in the U.S.A. and Canada by Kluwer Academic Publishers,

101 Philip Drive, Norwell, MA 02061, U.S.A.

In all other countries, sold and distributed by Kluwer Academic Publishers Group,

P.O. Box 322, 3300 AH Dordrecht, The Netherlands.

Paperback available from:

EUR. CONF. ON SCIENCE AND RELIGION

c/o J.W.R. Fennema CS

Postbus 665,

1200 AR Hilversum, The Netherlands

ISBN 90-365-0324-8 (PB)

Cover and lay-out:

Videac, University of Twente,

Enschede, The Netherlands

Printed on acid-free paper

All Rights Reserved

(C) 1990 by Kluwer Academic Publishers

No part of the material protected by this copyright notice may be reproduced or utilized in any form or by any means, electronic or mechanical, including photocopying, recording or by any information storage and retrieval system, without written permission from the copyright owner.

Printed in the Netherlands 


\section{Contents}

Statement of Intention

p. 8

Preface (Jan Fennema, Iain Paul)

p. 9

An encounter between science and religion;

preliminary observations (Jan Fennema)

p. 13

\section{Part I Lectures in full sessions}

\section{Epitome of Part I}

p. 26

\section{Introduction to the conference theme}

A.G.M. van Melsen, Science and religion

p. 27

T.F. Torrance, Fundamental issues in theology and science

p. 35

M. Bloemendal, Science and religion - the Jewish position

p. 47

Reconciling developments in the natural sciences - the question of scientism
A. Gierer, Physics, life and mind
p. 61
W. Weidlich, Reconciling concepts between natural science and theology
p. 73
J.C. Polkinghorne F.R.S., A revived natural theology
p. 87

Reconciling developments in theology - the question of dogmatism

W.B. Drees, Theology and cosmology beyond the Big Bang theory

p. 99

J. Van der Veken, God's world and man becoming:

how can science possibly help us transcend dogmatism?

p. 131

The divorce of science and religion - a process in retrospect

O. Pedersen, Historical interaction between science and religion

p. 139

J.R. Durant, Is there a role for theology in an age of secular science?

p. 161

Science and religion studies today and tomorrow

J. Hübner, Science and religion coming across

p. 173

G. Vahanian, Creation and Big Bang: the word as space of creation

p. 183 


\section{Part II Contributions in sectional meetings}

J.A. Mawuli Awudza, Science and religion: a Ghanaian perspective p. 194

R. Becerra-Acevedo, The mystical ideal and the humanistic ideal

within the world of ideals in the sciences

p. 195

G.J. Béné, Scientific truth and religious truth

p. 196

P.W. Böckmann, Two approaches and one reality:

on religion and the perception of the Cosmos

p. 197

S.L. Bonting, Man and the high-technology society

p. 198

M.E. Carvallo, On David Bohm's theory of wholeness and implicate order: provisional notes, some of which with special regard

to the possible applications to the philosophy of religion

p. 199

A. Drago, A. Koyré and the metaphysics of modern science

p. 200

H. van Erkelens, The unus mundus (One World)

as meeting ground of science and religion

p. 201

A.D. Fokker, The play that is going on in the cosmic scenery

p. 202

B. Gaál, A report from the Reformed College of Debrecen

p. 203

G. Gaizler, Interdisciplinary lectures at 6 o' clock

p. 204

M. Głodź, Beyond the alternative: divorce or methodological chaos

p. 205

$\mathrm{H}$. Hafner, Neither divorce nor reconciliation:

is there a gospel for the sciences?

p. 206

M. Heller, The experience of limits: new physics and new theology

p. 207

I. Hofmann, Evolution and progressive revelation:

the Bahá' $i$ approach to a converging reality

p. 208

J. Wentzel V. van Huyssteen,

Beyond dogmatism: rationality in theology and science

p. 209

R. Kirby, Spirituality and science: summary of purpose and proceedings

p. 210

P.P. Kirschenmann, M.A. Maurice and A.W. Musschenga,

The unchanged relationship of theology and science

p. 211

R. Koltermann S.J., The concept of evolution:

its reception in philosophy and theology

p. 212

U. Krolzik, Secularization of nature during the early Enlightenment:

conceptions of water circulation as an impulse for secularization

p. 213

G. Lepoutre, The scientific mind and personal faith

p. 214

G. Medgyesi, The views of a Hungarian catholic scholar on evolution at the end of the nineteenth century

p. 215

C. Ouafo Moghomaye, Traditional religion and Christianity

p. 216

L. Morren, A generalized principle of complementarity - seen as a sign

p. 217

W. Noodt, Evolution and future of human possibilities of gaining knowledge

K.H. Reich, The relation between science and theology: the case for complementarity revisited

p. 219

p. 220

J. Scheer, Base the science-religion dialogue on facts, not on doctrines!

p. 221 
M. Siciński, The reconciliation of social science and theology: is it still not possible?

p. 222

G.J. Stavenga, A new perspective on reality

p. 223

J. Szél, Humanitas ecologica

p. 224

C. Wassermann, On a relativistic structure in theology

p. 225

H.J. Winkler, The Academy of Research of the Evangelical Church of the Union, German Democratic Republic, a research report

p. 226

J. Życiński, The split between science and religion and the doctrine of God's immanence in nature

p. 227

Part III List of names and addresses

p. 230 
W.B. Drees, physicist and theologian, Staff member of Bezinningscentrum (Interdisciplinary centre for the study of science, society and religion), Vrije Universiteit, Amsterdam, The Netherlands 


\title{
Theology and cosmology beyond the Big Bang theory ${ }^{1}$
}

\author{
Willem B. Drees
}

'The most miraculous thing is happening. (...) The physicists are getting down to the nitty-gritty, they've really just pared things down to the ultimate details, and the last thing they expected to happen is happening. God is shining through. They hate it, but they can't do anything about it. Facts are facts. And I don't think people in the religious business, so to speak, are really aware of this - aware, that is, that their case, far-out as it always seemed, at last is being proven.'

(...)

'Mr. Kohler. What kind of God is showing through, exactly?'

Dialogue between a computerfreak and a divinity school professor, in

Roger's Version by John Updike (1986, p. 10).

\section{Contents}

1. Introduction: why do theology and science

2. What do we do in theology and science?

2.1 No need for religion and science!

2.2 The highroad of metaphysics

2.3 Theology interpreting science and explicating faith

2.4 Consonance: E. McMullin

2.5 Constructive consonance

3. Theology in the context of astrophysical cosmology

3.1 A beginning?

3.1.1. Limitations of the Big Bang theory

3.1.2. Diversity at the frontier

3.2 Complete theories of everything, contingency, and God

3.2.2. Quantum cosmology without initial conditions

3.2.3. Three inadequate responses

3.2.4. Types of contingency and the mystery of existence

3.2.5. The relevance of transcendence against holism

3.3 A dynamic or a timeless universe?

4. Down to earth: the integrity of creation 


\section{Introduction: why do theology and science?}

When pressed to explain why one should relate theology and science*, two kinds of answers are often given. On the one hand, ethical issues surround the application of science. The place of values in a world dominated by science must be determined. And in that context scienceand-religion* sometimes is even seen as necessary for the continued existence of life on Earth. On the other hand, relating theology to science might be necessary for the intelligibility and credibility of faith and, therefore, for the continued existence of Christianity in our time.

However, integrating science and theology at an intellectual level will not solve the moral issues of our time. Emphasizing the 'Integrity of Creation' might contribute to responsible behaviour, but the relevance of the churches should not be overestimated. Besides, as much confusion exists inside the churches as outside them. Nor will relating science and religion lead to increasing church membership. Instead, growing churches will probably continue to be mostly those that offer a simple package of opinions and guidelines; they provide a safety that relies upon an escape from the complexities of the modern world, science included.

Might we gain then by doing science-and-theology at the other end of the spectrum among those who take science seriously? A new religiosity, that is apparently based upon science, is now visible in the bookstores as a quest for 'holism'. Although its adherents seem much more promising as allies for those doing science-and-theology, this quest accentuates some important differences, especially with regard to the Christian emphases on a Beyond and on the significance of particular events and persons, all of which are more than a general immanent presence within creation. I am not too optimistic about the effect that science-and-religion will have on morality, church membership or Christianity. Spending time on it cannot be justified on primarily utilitarian grounds. However, I do believe that there are at least two good reasons for engaging in science-and-theology. To relate different kinds of human ideas is to respond to a thirst for understanding, one which appears to be widespread among human beings even when that understanding is not believed to be directly to their benefit. Curiosity seems to be one of the main driving forces behind fundamental scientific research as well as philosophy and theology. Honesty is another motive. We need to make sense of our scientific and religious ideas or else to forget them if we continue to fail to do so. But honesty need not be profitable.

Relating religion to science is the twofold task of changing the language used to express the religion and, thereby, changing the religion itself, and also of preserving those elements of the tradition that are still considered valuable. Such a project is similar to that of the feminist, black or other contextual theologies: that is, we are working on a reconceptualization while struggling to preserve the valuable elements of the classical tradition. It is not sufficient to make God-talk scientific talk, and thus a superfluous duplication ${ }^{2}$. We are also striving to sustain genuine God-talk.

There are many different approaches to science-and-religion. I will briefly consider some of them and also present my own version of constructive consonance between theology,

In relation to science the terms 'religion' and 'theology' are mostly used interchangeably. 
science and metaphysics (section 2). In section 3, I will look at 'theology in the context of astrophysical cosmology'. Granted cosmology is not typical of the sciences, but it does touch on many questions of philosophical and theological interest. Three aspects of the Big Bang theory, namely, the 'beginning', contingency, and the dynamic nature of the Universe, have been used in science-and-religion. I will argue that these issues lie outside the domain of validity of the Big Bang theory, and that a wide variety of ideas exist about theories beyond the limits of the Big Bang theory. In addition this discussion will illustrate some methodological aspects of the task of relating science and theology. To relate theology and science at the frontiers of scientific knowledge is quite different from, and sometimes much more interesting than, relating theology to the well-established consensus of scientific knowledge. It is at those frontiers that the monologue from science to theology may occasionally turn into a dialogue (section 3.1).

Some people claim that science is approaching a complete theory of everything. Is God then shining through or has God become a superfluous hypothesis? This issue will be illustrated by a quantum cosmology without boundary conditions. The discussion focuses on the anthropic principles, contingency and holism (section 3.2). Cosmology offers both a perspective from within time and a timeless perspective. I argue that this double description presents us with the opportunity to express constructively certain theological themes (section 3.3). Finally, section 4 reviews my ideas while contrasting them with the discussions of the World Council of Churches (WCC) on the theme of the Integrity of Creation.

\section{What do we do in theology and science?}

The task of relating science-and-theology is generally a rather vague one. The Second European Conference on Science and Religion was like a crowded market place with many individuals exchanging ideas in order to further their own particular programmes. I will look at a few approaches that I will use as stepping stones to my personal view of the nature of this task. Should theology adapt itself to the truths of science? Or does it function quite differently? Is theology leading or is it following science? Which one is supposed to change?

A second challenging aspect is pluralism. Does this variety of views result from some basic limitations on our part? If we were sufficiently clever and suitably open-minded, could we agree on a unique way of putting everything together? Or is pluralism inherent, with each individual left to make his or her personal synthesis as if anything goes? The position I wish to defend lies somewhere between these two extremes. In several respects this task resembles the building of a house: there is more than one way to put the bricks together. A building plan is required. But not every building plan is acceptable. There are rules restricting the number of realizable plans, for instance, those governing the stability and strength of the construction. This model suggests a pluralism of overall plans according to which the bricks from science and religion are put together. However, if some novel aspect of a plan turns out to be exceptionally important, then it is always possible to search for other kinds of brick. Neither science nor theology is beyond change. 


\subsection{No need for religion and science!}

We begin with pluralism. According to some people, science and religion are building different houses with different bricks and different plans on different grounds. There is no interaction; they do their own things. This is - broadly speaking - an existentialistic position which locates faith exclusively in the personal realm in such a way that it is supposedly out of touch with science. This approach eliminates many questions.

A strategic objection to this approach is that the 'safe domain' of faith might be more like an iceberg than like a rock; that is, it might be melting away! A philosophical objection is that it is simply impossible: the words of one domain are related to those of the other, and values imply assumptions about the way the world is. A theological objection is that it attempts to restrict God's relevance to an unacceptably small domain. In the Christian tradition with its notions of covenant and conversion, personal aspects are essential - and that is the 'truth' of the existentialistic position. But these aspects get their force and urgency through their embedment in a relation to God who is claimed to be the Only One, the Ground and Ruler of all.

A similar invalid reduction is associated with the great emphasis placed on language games. American theologians, like Ronald F. Thiemann (1985) and George A. Lindbeck (1984), have argued that we should accept religious pluralism and search for our strength by focusing on our own traditions. For truth is in use, that is, in the life of the community. Theology is dogmatics, not apologetics; it is internal discussion within a system, not the justification of a view to those outside. Such a retreat to individual traditions is unsatisfactory for reasons very similar to those given above. The unity of the sciences, despite the multiplicity of disciplines, challenges any easy acceptance of religious diversity even before trying to enter a rational dialogue. And apologetics is a part of science; one argues partly for the benefit of those outside one's research programme that one theory is better than another. Besides, science is always changing. Therefore, coupling a dynamic science to a static theology, that preserves unchanged its tradition, is mismatching them, for it is like putting new wine in old vessels (cf. Matt. 9:17).

For those who take science seriously, a more interesting defense of separation is the one presented by the English philosopher of science, Mary Hesse. She acknowledges science as a constructive activity underdetermined by observations. Future science will conceive of the fundamental nature of things very differently from present science. Science is progressive in its knowledge, but 'it is the kind of knowledge precisely appropriate to prediction and control. (...) It does not yield truth about the essential nature of things, the significance of its own place in the universe, or how it should conduct its life' (Hesse 1975, p. 389).

There is indeed a genuine distance between scientific theories and reality 'an sich' ('in itself'). But the conclusion need not be that science is only relevant to prediction and control and thus irrelevant to the things in which religion is interested: value and meaning, the essential nature of things. Science is a construction based on 'data' that relate it to reality while constraining the construction considerably. There is some underdetermination but not total indeterminism. Science is our best available way to knowledge, but to a knowledge which is far more than prediction. Among its components is an understanding of how the world works. There is also a strategic reason for taking science seriously; it enjoys great 
credibility in our world. To be credible, 'myths' need to take science into account. Theology has a stake in a modest realism too, for 'trust in God' assumes something about reality. But theology has traditionally acknowledged that there is also a genuine distance between the images and the stories we use and the reality to which they intend to refer.

\subsection{The highroad of metaphysics}

In some theologies, for example process theology, metaphysics functions as a mediating partner between science and theology by placing their mutual influence and coherence in a wider perspective. The theology appears as the most fluid contribution as it is reformulated to fit the metaphysical scheme. And it also seems to me that the metaphysics often determines the way the science is understood; the modern understanding of biological evolution, quantum phenomena or time being very much to the point. While I agree about the unavoidability of metaphysical elements, I have doubts about their dominance. Should one start with a metaphysics or at least get there shortly after take off? This approach builds in coherence, but it does so at the risk of forcing either the science or the religion, or perhaps both (for a similar criticism see Plomp 1987). Besides, it raises the problem of choice: which metaphysics should be adopted?

\subsection{Theology interpreting science and explicating faith}

According to Phil Hefner, an American Lutheran theologian, theology should 'discern how the world scientifically perceived is referable to God and how it can be the effect of God' (Hefner 1984a, p. 198). This position embraces an explicit asymmetry between science and theology. Theology has to live with the world as perceived through science. While theological arguments do not count in scientific discussions, science can falsify theological views. Interpretation is essential for meaning. As we don't find meaning at hand, we construct it with our interpretation. 'We struggle, as the poets often remind us, to forge meaning, and we try to test our forged meanings to determine their reliability' (Hefner 1984b, p. 484). It is a view that grants science its autonomy. In sharp contrast the theologian accepts humbly the conclusions of science, adapts his concepts, and changes his construction. But Hefner also acknowledges explicitly the traditional theological elements 'in their identity-bestowing role' (Hefner 1984a, p. 199).

I find myself in sympathy to some extent with this description of what usually happens. However, it turns 'science and religion' into too much of a monologue from science to theology. The interaction is certainly asymmetric, but there may be some influence in the other direction, especially if the constructive side of science is taken into account. Within science scope for construction exists by virtue of the distance between science and reality, and this scope makes theological or metaphysical influence on science possible. I will return to this point in my own proposal and illustrate it in the section on contemporary cosmological theories.

A similar position, which places a much greater emphasis on theology as an independent source because 'it begins with an experience with the Beyond', has been taken by another American Lutheran theologian, Ted Peters. He has argued for the use of scientific language and imagery in theology in the service of evangelical explication: 'Theology may begin with 
an experience of the Beyond, but it does not end there. It seeks to explicate the experience in terms of the scientific knowledge available' (Peters 1984, p. 388).

The German theologian Wolfhart Pannenberg claims even more for theology. He entitled an article, 'Theological questions to scientists'. As he sees it, there is scope for questioning in the opposite direction. For example, he asks whether science should revise the principle of inertia (mass continuing in rectilinear motion) or its interpretation because in its present form '[it deprives] God of his function in the conservation of nature' (Pannenberg 1981, p. 6).

I think this is a legitimate position: a certain element of one's theological system might be considered so essential that one prefers to question the science rather than the theology. Science is an enterprise in which conceptual shifts are legitimate. A theological perspective might provide sufficient reason to seek a definite modification of the science - a change of concepts or perhaps only a reinterpretation. Such an eventuality fits neither Hefner's nor Peter's description, both of which take science for granted. Clearly, interpretation and evangelical explication need to be supplemented in some way.

\subsection{Consonance: E. McMullin}

The Catholic philosopher Ernan McMullin (1981, p. 52) introduced the image of consonance which he defined as coherence in a world-view: 'The Christian cannot separate his science from his theology as though they were in principle incapable of interrelation. On the one hand, he has learned to distrust the simpler pathways from one to the other. He has to aim at some sort of coherence of world-view (...). He may, indeed he must, strive to make his theology and his cosmology consonant in the contributions they make to this world-view.' Admittedly there is a strong but tacit assumption behind McMullin's view. Consonance seems to involve more than the logical requirement of non-contradiction. It assumes that there is a relevant and largely independent theological contribution, and that the two contributions have to be made to fit 'in harmony'. These assumptions can be defended theologically (everything has to be related to God), or by an appeal to reality (maps of the same reality must show some correspondence), or psychologically (internal tensions within the faithful scientist must be avoided).

This approach allows both science and theology their freedom. However, as McMullin's writings (1981, 1985) make clear, it is not strictly true that the one is independent of other. Theological views incorporate some 'science', often the science of a distant past or some popular ideas about 'the way the world is' and about 'true knowledge'. The influence of theology on science is less visible. More often, the world-view is already there, influencing the theology and the science, for instance, through criteria that determine the preferences among theories and among possible interpretations. Many examples can be cited from quantum theory (regarding the nature of reality) and from thermodynamics (concerning the nature of time). Conceptually there is no unique genetic order of the three: science, theology and the world-view or metaphysics.

Consonance is open to the reality of pluralism: a song can be accompanied in a variety of ways. However, part of this openness is due to vagueness. Given sufficient ingenuity in 
constructing world-views, almost every religious conviction can be made compatible with almost every scientific theory. If consonance is to be useful, it needs criteria that distinguish between genuine consonance and ad hoc constructions - like the criteria for distinguishing between scientific progress and ad hoc adaptations (Lakatos 1970).

Consonance is based on epistemological realism about both science and theology. Many leading persons in science and theology have defended a critical realist view of both science and theology (e.g. Barbour 1974, McMullin 1981, 1984, Peacocke 1984, Polkinghorne 1986). The philosophical literature describes a variety of forms of realism (Leplin 1984, McMullin 1986), some based on the 'approximate truth' of theories, others on the 'reference' of the central theoretical terms to reality. However, each specified form of realism has its troubles (e.g. Laudan 1984a,b, Fine 1984) ${ }^{3}$. I share the realist attitude, recognising both that there is an external reality (ontological) and that science is telling us something about that world (epistemological). The same should hold for theology, if faith is to be true and comforting. But both enterprises also have a genuinely constructive side that accommodates a significant distance between our ideas and reality.

So far we have not met objections of a theological nature. In fact, the pursuit of consonance fits well with the protestant rule of sola Scriptura (Scripture as the only norm for theology). However, this rule is itself problematic. We always approach persons and texts equipped with our prior assumptions. This problem is, of course, a well-known aspect of 'hermeneutics': how do we bridge the gap between a text and ourselves when we cannot get away from ourselves, when we have 'glasses' that shape and distort our view of the text? This question amounts to a reformulation of the first objection given above: we cannot first take the two as entirely independent, then look with an open and clear mind to see if there is consonance. Clearly, consonance is not merely descriptive. For something has been built in from the very beginning by the language we use and by the way we interpret our concepts.

\subsection{Constructive consonance ${ }^{4}$}

In order to understand the intellectual side of science and theology, and in line with what was expressed by Hefner and Peters, I propose to use consonance as a constructive principle, as a methodological assumption, operating not only for the construction of world-views, but also within theology, and to a lesser extent within science too. We use it in the interpretation of abstract concepts, be they theological, scientific or philosophical.

By assuming that consonance exists between a theological view and a specific scientific theory, one implies that one should search for a suitable interpretation of the concepts involved. Probably such a search places both sets of concepts in a (not necessarily complete) metaphysical perspective. As this search does so, it is not only the world-view or the metaphysics that changes. The terms at the theological and scientific levels can also change meaning. Precisely what gives way and what remains unchanged depends on the relative importance of the various elements and on their reliability. In general, the science is considered to be the most reliable. In such cases, my proposal resembles an interpretation of the world as known through science: we reflect upon the knowledge provided by science and develop contemporary concepts to express our faith. 
However, science allows for different interpretations, e.g. in quantum theory. Moreover, science is always changing. In fact, Pannenberg appealed directly to the possibility of change with his question about inertia, thereby showing that the corresponding theological element was very important to him. At the frontier, where science is dealing with unsolved problems, there is a variety of ways to go. In such cases, a metaphysics informed by a religious perspective might determine the criteria for theory development and appraisal. I am not suggesting that theologians should be directly involved in the development of science. There is already ample ingenuity within the scientific community without them and, in any case, a serious contribution has to be based upon an understanding of the technical details. What I mean is that there are within the scientist certain convictions - informed by a wider perspective, to which the 'theology' of that person contributes - that occasionally play a role in the development of scientific theories. Not only in the context of discovery, but also in the choice of criteria. And people involved in 'science and religion' could make this role more visible and thereby much more open to analysis. For example, the cosmologists of the Universities of Oxford and Cambridge, Roger Penrose and Stephen W. Hawking, differ considerably on issues such as time-asymmetry and the nature of quantum reality. Here there is no direct theological influence, but there is a metaphysical influence that also has some bearing upon the theological issues, for instance, upon the nature of history.

My notion of constructive consonance has some similarity to the interanimation theory of metaphors (Soskice 1985). Metaphors are neither mere substitutions of one term for another nor direct comparisons. Similarly, my aim with constructive consonance is not substitutions of scientific terms for theological ones or direct comparisons. When linked by a metaphor, the two terms with their 'different networks of associations' (Soskice 1985, p. 49) interanimate one another as the search for consonance adds to or changes interpretations of the concepts used. By putting the terms from different networks together something happens to them. So the claim that has been made for metaphors also applies to constructive consonance: it 'can produce new and unique agents of meaning' (Soskice 1985, p. 3).

Theology today wrestles with two problems: (i) Is it true? e.g. Does God exist? and (ii) Is it intelligible? e.g. What does it mean to talk about God or creatio ex nihilo? A solution to the second problem, intelligibility, does not imply truth. We can communicate concerning the question whether the 'Universe' is open or closed without knowing which is correct. These concepts might not even be applicable in future theories. By focusing on theories that are assumed to approximate reality from the outset, one might attack both problems at the same time with an interpretation or a world-view that is intelligible and that approximates truth. The requirement of constructive consonance is more modest. It is primarily suitable for working on the second problem by showing the possible meanings of concepts. By aiming at an interpretation in the context of a specific scientific theory, it is parasitic on the intelligibility of the scientific theory. Hence in so far as scientific theories are intelligible, the method is useful. A ridiculous exaggeration, of course, would be the objection that in this way the concept of 'heaven above' can be understood in the context of a flat earth, a false but nonetheless intelligible idea. With this type of treatment the method would be reduced to a mere play with words, as if 'anything goes'. 
Evidently constructive consonance is not pursued for its own sake but as the first step towards a credible view of the world. Through its achievements science has gained considerable credibility, whether philosophers of science credit this gain to its approximation of truth or to its method of testing (e.g. Laudan 1984b), or just do not explain it at all. Now, fortunately, it is not necessary to solve the age-old problem of how to relate ideas to reality prior to relating the ideas of science to those of religion. For the primary task in science and theology is to relate them using, as one source of bricks, the best science available. In conjunction with criteria for acceptable forms of consonance, this approach might prove quite restrictive on the selection made from the possible theological and metaphysical views. However, a genuine pluralism remains because different, metaphysical and theological contributions are always possible.

The acceptance of the plurality does not bring the discussion to an end, even if there is agreement about the science. In principle, it is still possible to analyze and to discuss other criteria that partly determine the credibility of any proposals that integrate theology and science. Several questions come quickly to mind. How well do they satisfy one's religious convictions and metaphysical intuitions? And how do science, theology and metaphysics fit together? Hence, the need arises for notions of simplicity, elegance and beauty.

Mary Hesse (1981, p. 287) stated the case admirably: 'the problem is essentially not one of scientific 'realism', but one of communicative strategy'. I agree. Arguing for the truth of religious convictions on the basis of scientific theories has failed far too often. In the dialogue between science and theology, it is much more promising to focus on intelligibility than to concentrate on truth. If there is a plurality of scientific views, for instance, on the interpretation of quantum theory, one should attempt to present the core of Christianity within each and every one of those frameworks in the same way as it has been presented in many different languages and cultures. However, the question of intelligibility is followed by one of credibility, as a step towards truth. The credibility of any theological position, of course, will be strengthened both by a clarification of the criteria for acceptable forms of consonance and by the use of credible science and philosophy.

\section{Theology in the context of astrophysical cosmology}

Recent understanding of the Universe confirms that we are an integral part of the cosmos. Almost every atom in our bodies has been involved in the nuclear processes within a star. Cosmology also shows an impressive coherence of large and small. Superclusters - clusters of clusters of galaxies of billions of stars - have arisen out of fluctuations that once were smaller than a proton. This coherence makes it possible to discuss the Universe as a single entity, and not as a mere collection. Hence, there are grounds for interpreting it as Creation. More specific theological claims related to the Big Bang theory have been made. For example, Big Bang theory indicates that the Universe had a beginning in time that resembles an initial act of creation 'out of nothing'. Also, the Big Bang theory shows the contingency of the Universe. The Universe could have been different (e.g. in density). Its specificity, therefore, indicates that somehow a choice was made at the beginning - a choice 


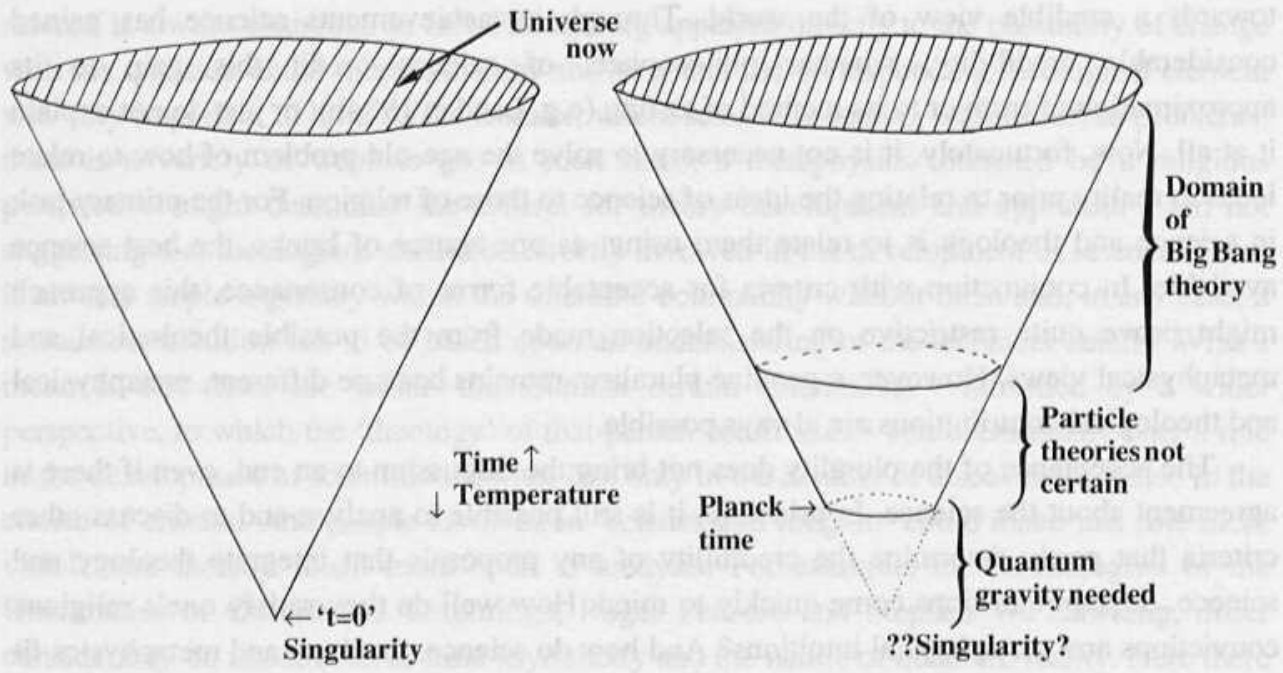

fig. 1

fig. 2

The Big Bang model.

Limits of the Big Bang model.

unexplained by science but explained by faith. The Big Bang theory also discloses a dynamic, evolutionary Universe. These three issues are discussed in the following sections.

\subsection{A beginning?}

\subsubsection{Limitations of the Big Bang theory}

The Big Bang theory describes our Universe as expanding from an infinitely dense and hot point, 'the Singularity'. As expressed in the title of Steven Weinberg's popular exposition, The First Three Minutes, it would appear that the Universe had a beginning, and that we can describe the relevant processes right from the start (see figure 1). As the latter claim is a widespread misunderstanding, we cannot be certain about the former claim either. The Big Bang theory has three limits that arise on combining two important theories: general relativity theory relating to space-time and quantum theories dealing with matter. The theories relating to matter are only known up to a finite density and temperature, that is, they are known not up to the ' $\mathrm{t}=0$ ' moment but only up to a fraction of a second later. Closer still to the Singularity there comes a moment, presumably the Planck time $\left(10^{-43}\right.$ seconds), when general relativity theory needs to be superseded by a quantum theory of gravity. And the Singularity itself is a third limitation, if there is such a thing as a Singularity in theories that describe the Universe before the Planck time. The first two restrictions are clearly limits to our knowledge, while the third appears to be the edge of reality. But the Singularity is hidden behind the other two limits to our knowledge (see figure 2) and in fact might be non-existent.

The Big Bang theory assumes some initial conditions, for instance, large-scale homogeneity peppered with just the right amount of inhomogeneities to produce galaxies. This 
theory also assumes that the Universe has certain general features: the laws of physics, three spatial dimensions and one dimension of time, and the very existence of the Universe itself. The great challenge for physicists has been to explain those assumptions and to extend the domains of validity of the various theories in question. A particular concern has been the development of more complete theories (to be discussed in section 3.2). First, we will focus our attention on the initial conditions and on the Singularity as an (apparent) origination event.

\subsubsection{Diversity at the frontier}

\section{Initial conditions}

Some scientists defend a chaotic cosmology. They point out that the initial conditions of the Big Bang theory might be irrelevant. In this case, almost anything goes. It is like a sandy beach: almost any initial conditions - with or without sand castles - will result in a similar smooth beach after the lapse of sufficient time. In its most recent forms this approach is based on so-called inflationary scenarios (Andrej D. Linde, Allan H. Guth).

No boundary conditions, and therefore the absence of choice, is the proposal of the Cambridge cosmologist, Stephen Hawking. 'It would mean that we could describe the Universe by a mathematical model which was determined by the laws of physics alone' (Hawking 1984, p. 358f). This proposal will be discussed in some detail below (section 3.2.2). According to him, physics is fundamentally time-symmetric. His acceptance of the so-called Many Worlds Interpretation of Quantum Theory means that, for a given probability distribution, there is no choice left: all possibilities are actual.

The initial conditions were special according to the Oxford cosmologist, Roger Penrose. Our kind of universe is very rare among the set of all possible initial conditions. Penrose described this rarity using the image of the Creator picking one of the possible initial conditions (Penrose 1981, p. 249; it seems that the religious vocabulary is used only as imagery). He combines this selectivity with a strong emphasis on time-asymmetry. Moreover, he argues for a change in quantum theory that does away with the 'interpretation' problem, thus bringing this theory closer to a notion of 'objective reality' (Penrose 1987).

The differences between these three approaches are partly due to various metaphysical ideas about time and the (dis)similarity of future and past, about reality and potentiality, influencing the science especially in its criteria for theory choice.

\section{The origination event}

All current discussions of the 'origination event' use the recent conclusion that the Universe might be equivalent to a vacuum. There are no conserved physical quantities that have a non-zero sum over the whole Universe. Either the sum is zero (e.g. electrical charge) or the quantity is not conserved (e.g. baryon number which makes the distinction, for instance, between protons and anti-protons). Even the total energy is zero, or not conserved or not a meaningful concept.

Discussions about the origination event have to go beyond the first two limits sketched above, so they need to propose some ideas about quantum gravity. But most proposals are 


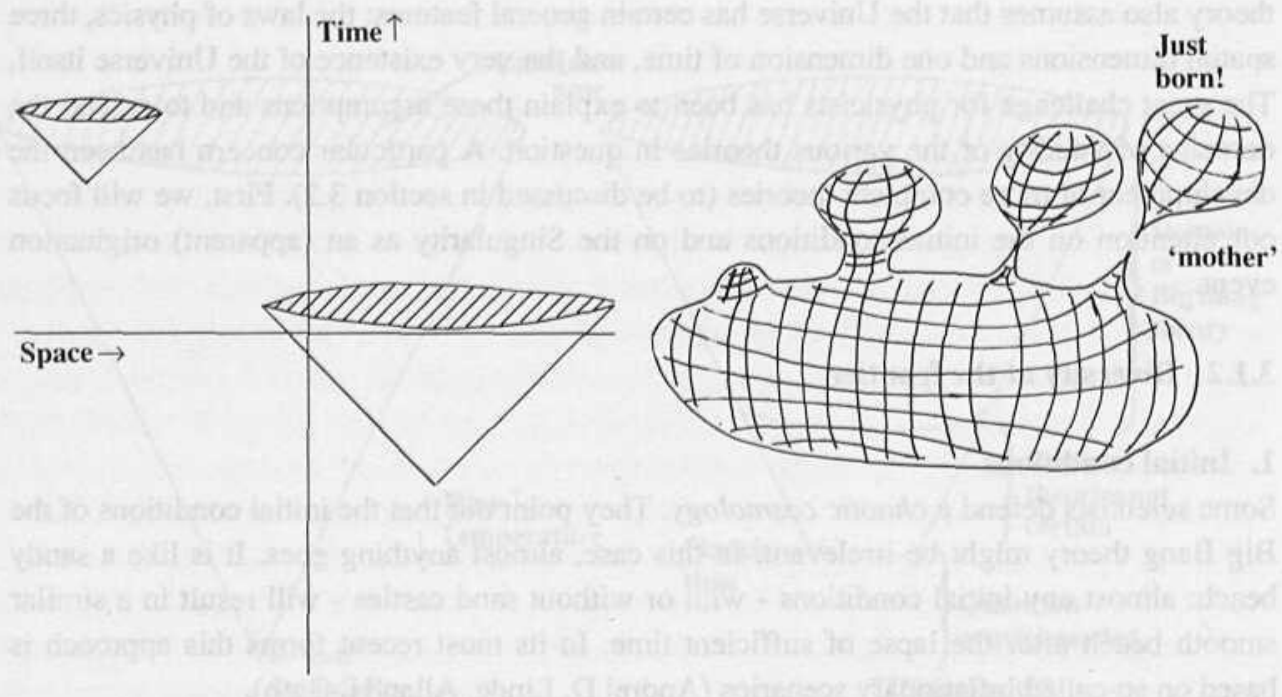

fig. 3

'Baby-universes' within an embedding space-time. fig. 4 'Baby-universes' which become spatially disconnected from the 'mother'.

not too dependent on the details: they are more like visions guiding current research. There is always, of course, the idea of an eternally oscillating universe. According to the Russian cosmologist M.A. Markov, the major advantage of this model is that it involves 'no problem of the origination of the world' (Markov 1983, p. 353).

The Singularity might be something like birth or conception, being, as it were, the beginning of time from the perspective of the baby or an event in time as seen by the mother. As 'conception' the Universe is like a bubble within an embedding space-time (Brout et al 1980, Gott 1982) (see figure 3). However, such babies tend to fill (and exhaust) their mother's womb (Linde 1983b). The model of 'birth' fares better: a mini-universe appears as a bubble on the 'surface' of the mother and, after evaporation of the connection, it becomes spatially disconnected (see figure 4). Andrej Linde has recently proposed an inflating universe consisting of bubbles, some of which inflate to sizes far larger than our observable Universe. As, in this kind of universe, there would be no first or last bubble, there would be for the whole no beginning or end of time either - although each bubble would have a beginning, and some of them also an end.

Such ideas might be formulated in terms of vacuum fluctuations, similar to the sudden short-lived appearance of an electron, an anti-electron and a photon together. As creation theories, such ideas are 'incomplete' because they assume the pre-existing spacetime framework in which the fluctuations occur. Other ideas attempt to evade this difficulty, basically by embracing the concept that 'time' is part of the created order, not prior to it. Appearance out of nothing has also been discussed repeatedly within the last few years (Vilenkin, Hartle and Hawking, Zeldovich and Starobinsky). Even if one disagrees with the philosophical ex nihilo interpretations of such theories, they do relate to traditional 
metaphysical questions, e.g. 'Why is the Universe as it is?' One of the most promising proposals of this kind will be outlined below (section 3.2.2).

\subsubsection{Five implications for science and theology}

1. The temporal cosmological argument (e.g. Craig 1979), which argues for the existence of God on the basis of a beginning of the Universe, is not univocally supported by science as it goes beyond the Big Bang theory. It is not too surprising that theologians and philosophers are not well informed about current research, but it is a serious failure on their part to neglect the limits of the theories they do use.

2. Many contributions to 'science and religion' concentrate on the methodological issues, but science is also theologically relevant for its content. For instance, Hawking has quite a different view of the nature of time from Penrose, a difference that has an important bearing on many theological issues.

3. Many people active in 'science and religion' restrict themselves to those areas where science shows a consensus. In the examples given the interesting issues lie clearly not in the Big Bang theory, but just beyond its limits in current research. What then is the actual relevance of established scientific theories for the science-and-theology dialogue?

4. If we leave the domain of consensus, we must face the variety of approaches at the frontier of research. Should we then on pursuing 'science and theology' restrict ourselves to the most promising ideas, pick the one that fits best our personal view, or wait until there is a consensus? If we look primarily for intelligibility, as I have advocated, we can take a look at as many approaches as are feasible in order to learn from each what we can and cannot say meaningfully about theological concepts.

5. Metaphysical influences on scientific research are also worthy of discussion. The differences between Hawking and Penrose on the nature of time, on the interpretation of quantum theory, and on many other issues are associated with metaphysical convictions about the nature of reality and about the relation between the potential and the actual. I think that 'the positive heuristic' is the place to locate such metaphysical influences (cf. Lakatos 1970).

\subsection{Complete theories of everything, contingency, and God}

\subsubsection{The challenge: complete theories of everything}

Stephen Hawking entitled his 1980 inaugural lecture for the Lucassian chair (Newton's Chair) in Cambridge 'Is the End in Sight of Theoretical Physics?' He considers it quite possible

'that the goal of theoretical physics might be achieved in the not too distant future, say, by the end of the century. By this I mean that we might have a complete, consistent, and unified theory of all the physical interactions which would describe all possible observations'. 
Complex phenomena might be beyond our calculative capacities, but we would have a complete and unified theory. In his view, a complete theory contains both the laws and the boundary conditions. The laws might be superstring theories. As far as understood today, the number of possible consistent theories is very limited. As regards the boundary conditions, Hawking (1980) says that many people

'would regard the question of initial conditions for the universe as belonging to the realm of metaphysics or religion. (...) I think that the initial conditions of the universe are as suitable a subject for scientific investigation and theory as the local physical laws. We shall not have a complete theory until we can do more than merely say that 'things are as they are because they were as they were'.'

The challenge was put more polemically by Peter W. Atkins (1984, p. 17):

'I am developing the view that the only way of explaining the creation is to show that the creator had absolutely no job at all to do, and so might as well not have existed. We can track down the infinitely lazy creator, the creator totally free of any labour of creation, by resolving apparent complexities into simplicities, and I hope to find a way of expressing, at the end of the journey, how a non-existent creator can be allowed to evaporate into nothing and to disappear from the scene.'

As God becomes unnecessary to the explanations, 'the hypothesis can be dropped'. Many theologians would be willing to accept the disappearance of such a creator, since Atkins' 'Creator' is too much of a 'God-of-the-gaps', that is, of the not-yet-explained. But some other well-known theologians object to the complete disappearance of God from the explanatory scene. Wolfhart Pannenberg (1981, p. 4), for instance, said:

'If(...) nature can be appropriately understood without reference to the God of the Bible, then that God cannot be the creator of the universe, and consequently he could not be truly God and could not be trusted as a source of moral teaching either.'

Pannenberg refers to the intelligibility of the natural order. But the contingency of that order may be involved as well. Thomas F. Torrance (1981, p. 85) emphasizes contingency alongside order. He holds that there is a contingency implied not only 'at the beginning', but also when order as orderliness is discerned:

'Today natural science assumes both the contingency and the orderliness of the universe. The universe is contingent for it does not exist of necessity; it might not have been at all and might very well have been different from what it is.'

Would a complete theory of everything do away with those two kinds of contingency, thereby making God superfluous and so denying God's reality?

First, I will say something about Hawking's quantum cosmology without boundary conditions. Next, I will point to three inadequate responses to modern cosmology: Richard Swinburne's non-temporal version of the cosmological argument for the existence of God, Stanley L. Jaki's use of the limitations of science, and the anthropic principles (section 3.2.3). Then I will describe types of contingency, emphasizing the mystery of existence 


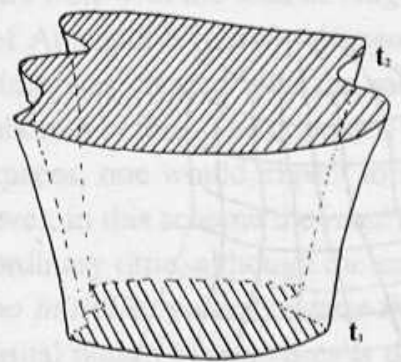

fig. $5 \mathrm{a}$

The state of the Universe at $t_{2}$

'arises out of' the state att 1 .

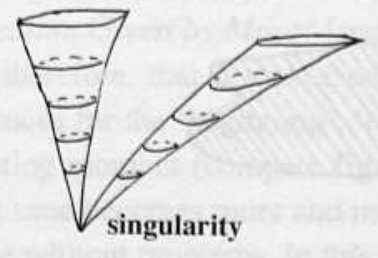

fig. $5 b$

More than one possible universe

starts off with a singularity.

(section 3.2.4). I will also stress the importance of retaining a notion of transcendence contrary to much modern spirituality (section 3.2 .5 ).

\subsubsection{Quantum cosmology without initial conditions}

The present discussion of this theory is not an attempt to defend it as a reasonable physical theory. That is not the job of someone who is interested in 'science and theology'. In any case, this theory has elicited many positive responses within the specialized literature. I accept, therefore, that it is a theory that deserves to be taken seriously. For present purposes this theory functions as a premise in a thought experiment: if one accepts this theory, what would that entail for theological reflection?

In the Big Bang theory, the state of the Universe at one time (the three dimensional geometry and matter) can be calculated using the equations and - as boundary conditions - its state at another time. In this sense one could say that a certain state 'arises out of' - or 'is created out of' - another state (see figure 5a). In the Big Bang theory the limit of such previous states is the initial Singularity. It is impossible to specify data at the Singularity; many different possibilities may start off with one-and-the-same initial Singularity (see figure $5 b$ ).

In quantum cosmologies a similar procedure holds. The Wheeler-DeWitt differential equation governs the evolution of a wavefunction. If one specifies the wavefunction at a boundary, it is possible to calculate it at other moments. In this way one could still look upon it as describing an evolutionary Universe. The disadvantage of this approach is that one needs to specify an initial or boundary condition. This problem is solved by the Hartle-Hawking proposal. They found a way to calculate the probabilities of the different states of the Universe, the three-dimensional geometries and matter configurations, without 

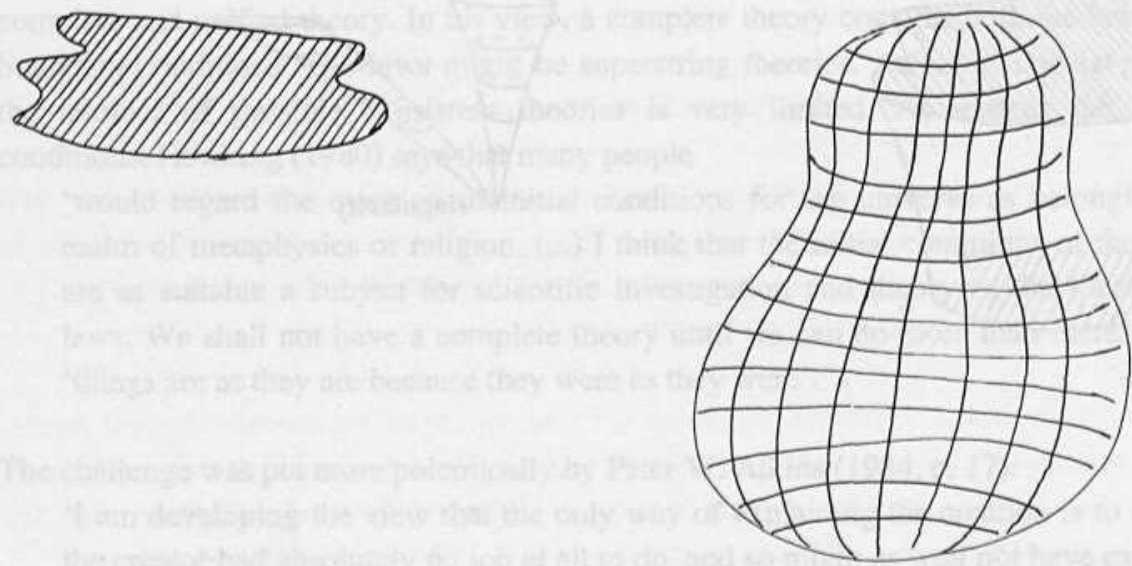

fig. 6 a

An open surface has a boundary.

fig. $6 \mathrm{~b}$

A closed surface has no boundary.

having to refer to other states or to evolution from such other states. This procedure is highly technical, but the essential idea is that one takes, not open 'surfaces' (or supersurfaces, for instance, three-dimensional spaces in an abstract four-dimensional space), but closed ones. These closed 'surfaces' (or closed three-dimensional spaces), which are the 'resulting' states, form the only boundary present in the calculation (see figures $6 \mathrm{a}$ and $6 \mathrm{~b}$ ). That is the precise sense in which this description can be taken to describe creatio ex nihilo: a calculation for one state does not require the prior specification of other states.

However, ordinary time together with the notion of 'becoming' disappear through the device of taking one closed 'surface' (or space) instead of an initial state at $t_{1}$ and a final state at $t_{2}$ (compare figure 5a). Therefore, expressions like 'tunnelling from nothing' do not adequately describe the basic idea of this theory. Tunnelling* denotes a temporal process, while the 'from nothing' applies to a kind of time-independent actuality. This anomaly, of course, affects the understanding of the word 'creation', if it is used in this context. One might say that the Hartle-Hawking theory does without initial conditions, but one could say equally well that it is a proposal for the specification of a boundary condition. The proposal is so interesting because it appears to be an elegant way of specifying the boundary condition. It is a choice that avoids a total arbitrariness.

There is no external time parameter in this theory. Time arises as a phenomenological construct out of the specifications of the geometry and matter (fields). Therefore, this theory

*

The term 'tunnelling' is applied, originally in quantum theory, when two given states influence each other while the penetration of the (energy) barrier separating them cannot be understood using the concepts of classical physics. 
fits well with the idea of Augustine (Confessiones, Book 11), and centuries earlier, of Philo of Alexandria (On the Account of the World's Creation Given by Moses [section 26]), that time was created with the material creation and, therefore, that it makes no sense to talk about a before. The approach clearly has consequences for the 'beginning', ' $t=0$ '. For small spaces, one would expect to approach this interesting moment (compare figure 5b). However, in this scheme the internal phenomenological time becomes more and more unlike our ordinary time, although the calculation can be done without problems. In this sense, there is no initial singularity where the theory breaks down. Only our interpretation in terms of the usual notion of time breaks down. To put it differently, there is no edge to reality, only an edge to our description (see figures $6 \mathrm{a}$ and $6 \mathrm{~b}$ ). By way of explanation Stephen Hawking referred on a number of occasions to the North Pole: the degrees latitude end there, one cannot go farther north. However, as a point on the surface of the Earth, the North Pole is not different. from other points: it is not a special edge to the Earth. In the context of the Big Bang theory, it is possible to have space with a finite volume but without edges, like the surface of the Earth which is a finite surface without edges. Due to their approach to 'time' Hawking and Hartle are able to achieve the same in four dimensions, i.e. a space-time without edges.

Traditional theological ideas about creatio ex nihilo have two poles. They refer to cosmogony, the coming into being of our Universe. And they denote an eternal sustaining by God, an ultimate dependence at each and every moment, the Universe having its Ground in God. It seems to be widely held that the latter pole 'is somewhat decoupled from modern scientific thought' (Isham 1988, p. 376). In point of fact the theory presented here lends itself much more readily to an interpretation in terms of sustaining than of making. The basic entities are the three dimensional spaces together with their material content. They are, in this context, the primary products of creation, the 'what' that is created. Their relative probabilities can be calculated at the timeless level. Viewed from the timeless perspective, they are all coeternal, that is, created 'timelessly'. Hence, all are equally related to the Ground of Being. Another route to the same conclusion is to argue that this scheme does not have an initial event with a special status. There is no way to pick one space as the first of a sequence. All moments, therefore, have a similar relation to the Creator. Either they are all 'brute facts' or they are all equally created.

To summarize, this theory allows a precise interpretation of the term ex nihilo, and it accommodates better the idea that every space (with content) is created by God than the idea that God created 'in the beginning'. Consequently, this theory is more consonant with theism than deism.

A final word of caution: this theory is not to be taken as the indubitable conclusion of science today. It is only one example taken from the many ideas discussed in the current literature, although it is one of the most elegant and coherent. Some of its features are typical of most quantum cosmologies. The special feature of the Hartle-Hawking proposal is its emphasis on the 'timeless' calculation without other boundaries, hence the 'from 
nothing' which can be understood as doing away with the related contingency too - and thus with God? This point brings us back to the main line of thought in this section.

\subsubsection{Three inadequate responses}

\section{Richard Swinburne's non-temporal cosmological argument.}

A non-temporal version of the cosmological argument, maintaining that the whole (possibly infinite) series of states needs an explanation, not just the initial state, has been defended by Richard Swinburne and by others too. The present research does not affect his argument that we have to face ultimately two possibilities: 'The choice is between the universe as a stopping-point and God as a stopping-point' (Swinburne 1979, p. 127). His argument for preferring God as stopping-point rests on the claim that 'God' is a much simpler assumption than the Universe alone with all its complexities. This claim is not in line with contemporary research. Scientific theories of the Universe gain progressively in elegance and simplicity - if not in the calculations at least in structure and assumptions - suggesting that these theories might provide a simpler stopping-point than 'God'. Simplicity is not the proper basis of an argument for transcendence.

\section{Stanley Jaki's limitations of science}

Complete theories seem to do away with mysteries. But Stanley Jaki (1982, p. 258) has followed the opposite course in arguing for the persistence of mysteries. Even a perfect scientific cosmology

"can never pose a threat to that cosmic contingency which is intimated in the scientific portrayal of the specificity of the universe'.

All specific entities - specificity being a sign of limitation - find their explanation in the creator, who is the totality of perfections.

'The cosmologist disdainful of metaphysics will be left with a formidable if not

frightening array of singularities, and the only scientific thing he can do about them is

to trace them to another array of singularities' (Jaki 1978, p. 273).

Such scientists do not reach a final explanation, but instead commit 'the fallacy of infinite regress'.

Swinburne argued for the greater simplicity of a theistic explanation, but he acknowledged the possibility of two stopping points: either the existence of a God who created the Universe or the existence of the Universe itself. Jaki seems to assume that only the first option is a sound metaphysical position; the second is discarded as incomplete and frightening. His approach does not do justice to the actual discussion. Those who argue from a non-theistic perspective might well assert on metaphysical grounds, invoking criteria of completeness, simplicity, beauty and coherence, that a certain explanation is satisfactory.

\section{The anthropic principles}

Standard cosmology assumes what is called the Copernican principle: we do not have a privileged position in space. Nevertheless, in the last few years, there have been rumours circula- 
ting that there is something special about us as expressed in the anthropic principles (Barrow and Tipler 1986). Those principles are related to a number of 'observed' features of our Universe. Because those features are thought of as necessary for the development of our kind of life, I prefer to call them 'anthropic coincidences'. For example, three dimensions of space appear to have significant advantages over two or four dimensions. Also, if the expansion rate of the Universe had been slightly greater or only a little less, there would not have been stars or there would not have been sufficient time for biological evolution, respectively.

The simplest version of the anthropic principle is the Weak Anthropic Principle (WAP), which states that what we see must be compatible with our existence. We see a Universe where there is carbon - because we depend on carbon, etcetera. Imagine the existence of many planets at different distances from their star and, therefore, with different temperatures. Since life depends on liquid water, life will only be found on planets with surface temperatures between zero and one hundred degrees centigrade. Well, there is nothing mysterious about that. There is no reason to call it 'a Principle'. It is standard use of evidence: we have A, we know that it needs B, hence there is $\mathrm{B}$. This usage does not explain why $\mathrm{A}$ and $\mathrm{B}$ are there. In my example, it does not explain why there are such planets or why there are such living beings. It only repeats the rule used in the inference: the two go together. The WAP does not explain anything - whether combined with many 'worlds' (in my example, planets) or not. It is not wrong, but irrelevant. However, those who assume the existence of many 'worlds', for example, Andrej Linde with his idea of bubble-universes, generally combine the WAP with the metaphysical principle: everything that is possible must be actual. If that additional assumption of plenitude is introduced, one might then explain observations by appealing to the selection effect embodied in the WAP. The interesting issue, however, is not the WAP but the view of the relation between the possible and the actual.

The more interesting, but perhaps also more repugnant, version is the Strong Anthropic Principle (SAP): the Universe must have the properties that will allow life to develop at some stage in its history. If by 'life' is meant 'life as we know it', the principle is of course quite strong in its predictions about possible universes. However, that conjecture is plainly untestable as we do not have access to other universes. Besides, it is somewhat post hoc, and it uses something (life), which in all its richness is only partly understood, in order to explain other things. Perhaps other forms of life will develop zillions of years from now at completely different stages of the Universe. SAP explanations are also vulnerable with respect to the future developments of scientific theories. According to the history of science, subsequent theories have generally fewer and fewer independent and unexplained parameters (constants, boundary conditions). Indeed, this erosion of assumed evidence for the anthropic principles has already happened a number of times (Pagels 1985, Gardner 1986). If applied on a smaller scale, say 'planets must have the properties which allow for the development of life at some stage in their history', then the principle is surely wrong. This example shows the true character of the SAP. SAP is like the old teleological argument that everything must have a function, and so the moon must be populated - as the ancient philosopher Plutarchus argued (Raingard 1934). 
There is another version of the Strong Anthropic Principle labelled the Participatory Anthropic Principle (PAP), which is based on an interpretation of quantum theory that ascribes enormous significance to the actual act of conscious observation, an act which gives reality to the past. According to John A. Wheeler, a universe needs to develop conscious beings who can observe their early Universe. Otherwise it will not come into existence. This conjecture might be accommodated readily by a metaphysics which gives 'minds in the Universe' priority over matter. As I find such metaphysics strange, PAP does not appeal to me.

From this sketch, I conclude that the strong anthropic principles are actually expressions of metaphysical principles in contemporary scientific language. As such they illustrate constructive consonance: different components are brought together and thereby develop certain meanings. One uses them only if one finds the implicit metaphysics compelling.

\subsubsection{Types of contingency and the mystery of existence}

The Hartle-Hawking quantum cosmology without boundary conditions does remove some contingency. For example, inflation* might turn out to be a necessary phenomenon within this scheme. But there are other kinds of contingency, so we have to see which kinds of contingency disappear.

\section{Contingency of the initial conditions.}

Most theories have a large set of initial conditions. Within the context of the pertinent theory they are all equally likely, if considered a priori - otherwise one would have an extra law and a different set of initial conditions would then be required. This kind of contingency disappears if physics and cosmology come up with a theory in which the set of possible initial conditions is empty (there is no need of initial conditions) or the set consists of only one element (which amounts to the same thing). In this sense, the Hartle-Hawking cosmology is a package deal: there can be no negotiations about details (like initial conditions) once the scheme is accepted.

Even if initial conditions are necessary, there might still be a second kind of contingency.

\section{Contingency of the laws.}

Why are the laws of physics what they are? Why is the Hartle-Hawking cosmology preferred and not another proposal, say Penrose's twistors? This line of inquiry seems safer ground for contingency. Complete theories of our Universe, as described by Hawking, need not be unique: there might be more than one (aside from trivial reformulations) which fit our observations. It is even more likely that there might be more than one consistent way to

* In order to solve problems in Big Bang theory it has been proposed that the very early Universe has known an inflationary phase of extremely short duration; inflation might explain, for instance, the absence of anti-matter in our universe. This inflation should not be confused with the expansion of our universe, which continues until the present time. 
set up a universe without the restriction that it is like our own. This likelihood is the contingency of the laws or the theories. In order to rule it out, one would require some kind of overview of all possible candidates for such theories, demonstrating that there is only one. That seems too strong a requirement. However, there might be only one theory which is consistent in all respects. Superstring theories are among the latest novelties of theoretical physics*; they are the best candidates available today, and their number is quite small. Six such theories are known to satisfy the required conditions of consistency, and perhaps three of them are actually equivalent. Additional conditions might reduce further the number of consistent theories. 'Ideally it will turn out that there is only one' (Schwarz 1987, p. 654).

Aside from all that, the contingency of theories is different from that of initial conditions. All possible initial conditions are equally good candidates a priori, but that does not hold for theories. For instance, there are variants of Einstein's theory of General Relativity that are compatible with present day observations. However, they are not considered to be as good as General Relativity itself. The criteria used in such evaluations include coherence, simplicity, and elegance. If one accepts such aesthetic criteria in addition to the requirement of consistency, the contingency of the laws might actually disappear in the not-too-distant future.

I am not sure that the two forms of contingency just discussed will ever disappear. However, even if it were to happen, there is no good theological reason for objection. It would do away, of course, with the fundamental role of experiments in science, and this would do away, in turn, with the argument that theology and science should remain friends because the theological idea of contingency made science possible in the first place (advocated by Jaki et $\mathrm{al}$ ). It would do away also with the role of experiments in science as an argument for contingency (e.g.Torrance 1981). Thus we would lose certain arguments, but we still might be grateful for the things that we would understand. It would show that the Creator had only one type of universe available - given the rules of logic and mathematical consistency as well as certain aesthetic preferences. In a way this is similar to the theological dispute between Leibniz and Spinoza. Had God a choice among possible worlds? Or does God's nature imply that God creates the best possible world? (Hubbeling 1987, p. 148) As far as I see it, God's personhood is not dependent on these kinds of contingency. The personhood of God is more expressive in relation to individuals and in the will to have a creation - which reflects the goodness of creation as a free gift. However, this expression is not dependent on these two forms of contingency, but leads us to a third.

\section{The contingency of existence.}

Why is there anything that behaves in accordance with the mathematical rules written down in the Physical Review (a famous journal of physics, read world-wide)? Some people, like Atkins, hold that chance phenomena are sufficient explanation; others simply identify their mathematical ideas and what they consider to be the actual universe ${ }^{5}$. But as I see it, probabilities alone are not enough; they need an input of actuality. The probability of throwing a number below seven with one die is one, it is certain, but only if there is a die which is thrown

In a string theory the basic elements are not mass points but vibrating bodies that extend in one dimension: strings. 
-hence, only if there is an actual die and a die factory, as well as a throw. Quantum fluctuations might do away with the throw - they happen all the time - but not with the need for some input of actuality. This kind of contingency lies beyond the limits of physics.

For a long time, I have considered this to be a stop-gap, a last resort for the theologian if there is nothing else left to claim. I still doubt whether it is useful in an argument for the existence of God. Nevertheless, this issue is related to a sense of wonder that, in my case, has increased steadily throughout my study of cosmological ideas. It has been aptly described by the physicist Charles W. Misner, who said that 'God blessed one formula in some creative act' (1977, p. 96). Whether or not it was the only beautiful formula available to God does not make any difference. Quoting Misner again,

'To say that God created the Universe does not explain either God or the Universe, but it keeps our consciousness alive to the mysteries of awesome majesty that we might otherwise ignore'.

To see the Universe as grace, as a gift, is a way of interpreting this sense of amazement and of relating it to an understanding of God. In this context a difference between theism and pantheism is clearly visible.

'We might perhaps define theism best by understanding it as that conception of God where the world is the product of God's free, self-conscious, creative and maintaining activity. This definition involves that God does not require the world for the realization of his being, because God creates the world freely' (Hubbeling 1963, p. 10).

\subsubsection{The relevance of transcendence against holism}

There is a new spirituality to which I alluded in the introduction, and which is variously labelled the New Age, holism, cosmic spirituality, etcetera. It offers a different answer to the last kind of contingency, namely, the mystery of existence: we can accept that the Universe just happens to be and still feel religious. Without attempting an exhaustive description and criticism (Restivo 1984), I respond to the challenge that it poses. As I see it, the challenge is against the transcendental component of Christianity, against the appeal to a God beyond the Universe. Why not instead label the whole 'God'? Or use that label for the final state? Or use it for the spirit or mind that pervades reality? There is surely something interesting and sympathetic about it. Often holistic views go with a responsible attitude towards nature and man together with an openness to poetry. Indeed, pantheistic systems can have great beauty and coherence.

I have two basic theological objections. Firstly, most holism neglects the brokenness of creation with its emphasis on wholeness. Too often, the only barrier seen is one of thinking, of knowledge. But the symbol of the cross expresses an element of realism about this world. The wholeness should be a vision rather than an unrecognized presence; it is more of a 'not yet' than of an 'already'. As a vision it transcends the actual universe. Secondly, holism tends to overemphasize the mystical ideal of the unity of the individual with the divine. Aside from having a mysticism of encounter in Christianity, that stresses the differences between the individual and the divine, there is also the prophetical side. In the prophetic tradition there is scope for criticism, because the God who is the source of the norms is not 
identical with the reality that surrounds us. Prophetic criticism rests upon a metaphysics which has a notion of otherness, an idea of transcendence. We need a difference between the Universe and the Beyond as the basis of the critical tradition that we have inherited, and that we require to preserve whilst changing.

\subsection{A dynamic or a timeless universe?}

Stephen Hawking said recently (Time, February 8, 1988, p. 60) about his own quantum cosmology:

'The universe would not be created, not be destroyed; it would simply be. What place, then, for a Creator?'

The Big Bang theory has often been understood as showing the dynamic, expanding and evolutionary nature of the Universe. I have no objection to that understanding other than that I think that it is a one-sided incomplete presentation. In physics there are often two descriptions, as we have seen in the Hartle-Hawking quantum cosmology: one can calculate the states not only by using a differential equation and an initial state, but also at a timeless level without referring to previous states at all. This theory is exceptional in that the timeless level of description involves individual spaces, that is to say, individual moments of 'now'. That raises some questions of its own, especially about the continuity of our experiences. However, the presence of two descriptions is not restricted to this exceptional (and still preliminary) theory. For instance, General Relativity, which is often understood as describing a dynamic expanding universe has as its most fundamental entity a fourdimensional spacetime. At that level of description, all moments are equally copresent. There is no way of talking at that level of description about things moving, changing, evolving and so on. The picture is completely 'static', because it makes no sense to talk about four-dimensional spacetime changing in time. A similar double description is also applicable to other theories, in which one can describe systems evolving in time also by their trajectories in phase space. Such trajectories represent whole histories at once. Theories formulated in that kind of language are not evolutionary. Instead, the theory is about different possible 'packages', complete histories, whereas the term 'evolutionary' is appropriate to another kind of description that is not timeless.

Almost all contemporary theologians who take science seriously opt for a dynamic picture. Scientists have discussed the problem of time extensively, and they have attempted to understand the arrow of time, the flow of time that is experienced. Theologians have always hoped for a favourable outcome of this discussion, since theology has an intense interest in history and, therefore, both in changes and in directionality (e.g. Griffin 1986, Russell 1984, Pannenberg 1981). I think that the presence of a double description in physics together with the differences between physics and biology provide theology with a welcome opportunity. This double description offers theology a valuable means of expressing different interests and of reflecting upon those insights, while their interrelation might be clarified by analogy to the correlation of its scientific counterparts. Here I cannot deal in great detail with this matter, so I will present only short summaries of the two descriptions which are more like members of a family than two precisely circumscribed unities. 
A description within time takes history and evolution (including cosmic, stellar, geological, biological and cultural elements) as basic. This kind of description resonates with a theological emphasis on 'Heilsgeschichte'- the 'history of salvation'. It leads to questions about causality and about the origin and purpose of processes. Creatio continua is the theological doctrine that deals with God's relation to the processes of change, especially God's relation to the emergence of novelty. This description also stresses the issue of contingency, as the things of today were different yesterday, and they will be different again tomorrow. Value is related readily to the future - what is produced by something shows its qualities. This is related to a teleological or utilitarian understanding of ethics. God's relation to the world is most easily formulated in terms of immanence or transcendence in a temporal sense.

A description beyond time might be understood as a view from God's perspective, sub specie aeternitatis. The whole of history is present at once. This raises far less questions about origins. Instead, the corresponding question is about the ground of everything. There is less emphasis on novelty - there can be nothing new if everything is presented in one overview - and more on permanent structures. Rather than emphasizing contingency, it pushes the idea of necessity- the eternal laws which are the same for all moments. Consequently, the sustaining element in traditional concepts of creatio ex nihilo, that is, the conservatio, has more emphasis. Value must be understood as belonging to every element by virtue of it being a part of the whole web. Transcendence is much more radical, completely outside the space-time description.

One could perhaps relate the two descriptions to emphases on God's activity and being respectively, or to the two different types of biblical literature, the historical and the prophetical within the history of Israel and the more distantial wisdom strand, which reflects on the way things are, will be and always have been.

\section{Down to earth: the integrity of creation}

I have looked at theology and science from an academic perspective. But what about its relevance for church and society? As a recapitulation and localization of my ideas, let me briefly point to some issues that have been discussed in recent WCC documents on the Justice, Peace, and Integrity of the Creation process.

\section{Method}

There is as much confusion about the relation between theology and ethics as in academic discussions about theology and science. Sometimes, it is claimed that an 'understanding [of the relationships between God, humanity and nature] is necessary to provide a framework for formulating value decisions on environmental issues' (WCC 1987c, p. 1). We must 'attempt to have a theocentric perspective of nature and this should be the basis of any Christian environmental ethic' (WCC 1987b, p. 41). This sounds as if theology is taken as the basis and ethics is derived from it. However, throughout the documents, it is amply clear that the ethical issues are incentives to reformulate the theology, and that theological approaches are also judged by their ethical implications. 


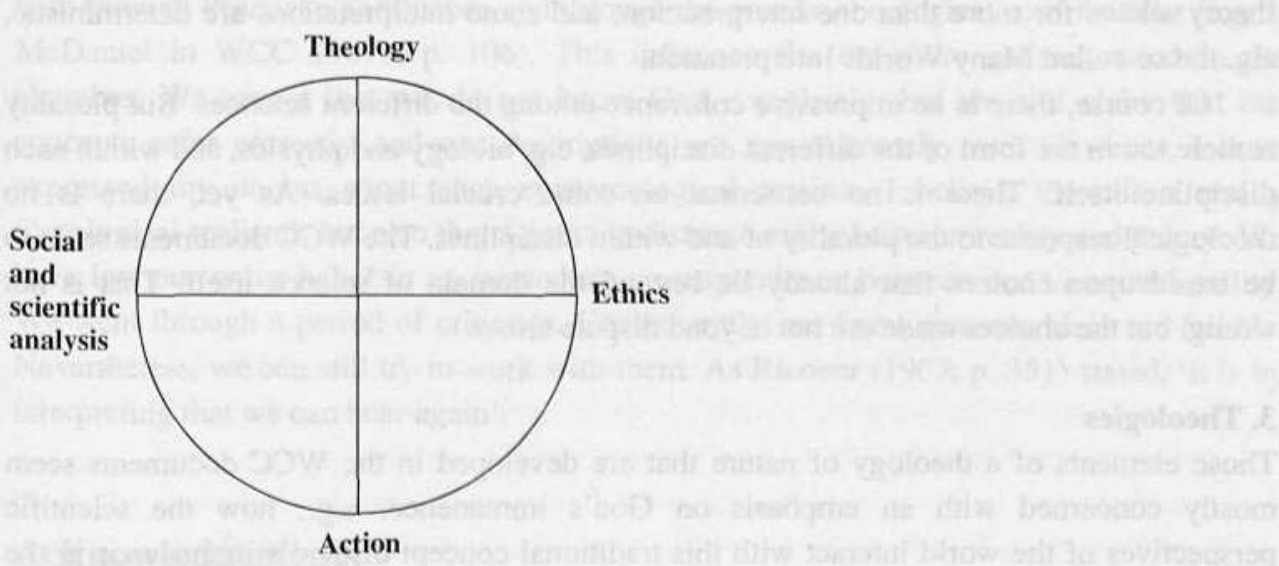

fig. 7

The 'Bossey circle': a frame for a pictorial evaluation of four aspects of a report or programme.

I have argued that natural science, theology and metaphysics mutually influence each other with different emphases placed on what is kept fixed in different cases. Something similar might be applicable here: theological and ethical reflection and ideas about how society works' come together. There is neither a unique temporal order nor one of priority. Each of them, theology, science, and metaphysics might change, but it also might be the core that is protected. Something similar might be read into the so-called Bossey circle (WCC 1987b) (see figure 7). It seems to be a tool for the description of the work done by others. But it is also a statement about what should be done (i) to cover those four issues indicated in the diagram, and (ii) to relate them and, if necessary, change them in order to give a consonant whole. The advantage of this approach would be its openness to the diversity of contributions from different sides - as present in the World Council and in society - while aiming at a wider perspective.

\section{Sciences}

There is a strong emphasis on biology - in line with the emphasis on environmental problems - in the documents of the World Council of Churches. Astrophysical cosmology is mentioned, but basically only as one of the many contributions to the overall picture of an dynamic and intelligible Universe ${ }^{6}$. Quantum physics is used partly to argue for a certain ontology (not substantial; subjectivity even for electrons, according to Charles Birch; relationality of everything), and partly to argue for freedom and responsibility. This discussion is stimulating and, perhaps, what should be put forward for a broader audience. However, as argued above, there are other aspects of current science that do not fit well. Especially troublesome in this respect are time, determinism, and creativity. Quantum 
theory allows for more than one interpretation, and some interpretations are deterministic, e.g. the so-called Many Worlds Interpretation.

Of course, there is an impressive coherence among the different sciences. But plurality is there too in the form of the different disciplines, e.g. biology and physics, and within each discipline itself. There is no consensus on some crucial issues. As yet, there is no theological response to the plurality of and within disciplines. The WCC documents seem to be based upon choices that already lie beyond the domain of science itself. That is not wrong, but the choices made are not beyond dispute either.

\section{Theologies}

Those elements of a theology of nature that are developed in the WCC documents seem mostly concerned with an emphasis on God's immanence, e.g. 'how the scientific perspectives of the world interact with this traditional concept of God's immanence in the world' (WCC 1987b, p. 38). In the documents transcendence is also affirmed, but 'immanence' seems to be the attribute that calls for development today, both in relation to science and as a basis for ethics. This emphasis on immanence leads to an identification of 'sustaining' with creatio continua: 'The traditional picture of God 'sustaining' the universe can now better be seen in terms of God's continuous creative action' (WCC 1987b, p. 40). However, I argued earlier (in line with Pannenberg's question about inertia $(1981,1988)$ ), that sustaining also has the meaning of conservatio, even if there is no change. This meaning links it more with creatio ex nihilo than with creatio continua. God can be seen as the permanent ground of everything, whether there is anything changing or not. I have also defended the theological importance of creatio ex nihilo in expressing the graciousness of creation, a notion that is played down in the WCC documents, because it does not fit well with the process-theological input.

Besides, I hold that the ethics should be based, at least partially, on God's transcendence and not on God's immanence. The WCC documents seem to look for a theocentric ethics through an emphasis on God's immanence in nature, e.g. 'God's presence in all creation reveals to us that in addition to human beings otiner creatures are also subjects that have a claim upon us' (WCC 1987b, p. 41; emphasis added). In contrast, I see as the source behind the criticism of the prophets not God's presence in the business of everyday living, but God's otherness.

I feel a little uneasy about my criticisms of the approach in those recent reflections on the Integrity of Creation. I agree that 'Justice, Peace and the Integrity of Creation' are major issues in the world today, issues with which Christians have necessarily to be involved. However, I must disagree with some of the theological ideas used without disagreeing about the other elements in the 'Bossey circle'. There is a plurality of acceptable theologies in today's world. But we need not let the matter rest there. We should find ways of clarifying further the nature of the differences and the agreements as well as methods of assessing which approaches are the most credible.

\section{Realisms and constructions}

One final reflection and comparison. The WCC documents are based on 'critical realism' 
both through Peacocke's influence and through the process-theological contributions (e.g. J. McDaniel in WCC 1987b, p. 106). This influence fits the more general mood in the churches. We accept that we do not know God completely, but we still claim that our concepts refer correctly and our descriptions are approximately true. However, I have expressed my doubts about such epistemological realism. I believe there is a reality (ontological realism), but also that a genuine distance exists between reality and theory. We have lost our naive belief in an immediate correspondence between our ideas and reality. We went through a period of criticism. Consequently, we know that our ideas are fallible. Nevertheless, we can still try to work with them. As Ricoeur (1967, p. 351) stated, 'it is by interpreting that we can hear again'.

\section{Acknowledgements}

I want to express my gratitude to Robert Russell and Phil Hefner, who contributed much to the development of my ideas as presented in this lecture. The contacts with them made my stay in the U.S.A. particularly fruitful, both at the Center for Theology and the Natural Sciences at the Graduate Theological Union in Berkeley (in the Fall of 1987) and at the Chicago Center for Religion and Science at the Lutheran School of Theology in Chicago (in the Winter and Spring of 1988). Also, I am very grateful that correspondence with Chris Isham has proved so valuable, especially to my understanding of the Hartle-Hawking theory.

These investigations were supported by the Foundation for Research in the field of Theology and the Science of Religions in the Netherlands, which is subsidized by the Netherlands Organization for Scientific Research (NWO). The period of study in Berkeley and Chicago was also supported by a Fulbright scholarship and additional financial support from the following Dutch organizations: Haak Bastiaanse Kuneman Stichting, H.M. Vaderlandsch Fonds, Vereniging van Vrijzinnig Hervormden te Groningen, Genootschap Noorthey, Fonds Aanpakken, and Groninger Universteits Fonds.

\section{Notes}

1. The ideas presented in this article have been developed in more detail in my Beyond the Big Bang: Quantum Cosmologies and God (to be published by Open Court, La Salle Ill. and London, 1990).

2. At the First European Conference on Science and Religion Viggo Mortensen expressed such a concern with respect to Ralph Burhoe's programme: 'When (...) God can be explained by genetics, then religion becomes nothing but words - words that we could just as well do without' (Mortensen 1987, p. 197).

3. The title of Ernan McMullin's book, Construction and Constraint (1988), suggests a very moderate form of realism - if one would still call it that - emphasizing the two elements I present below for science and theology. Perhaps, through the many qualifications (e.g. McMullin 1986), the author would not be that vulnerable to the philosophical criticism of realism. 
4. The formulation is my own, but I share many of the basic elements with Robert Russell in Berkeley, who influenced my ideas through many conversations and articles. Robert Russell analyzed, for instance, finitude and other elements of contingency in relation to the different possible Big Bang cosmologies. One of his conclusions was: The particular elements of contingency in a given cosmological model both interpret and limit the theological claim that creation is contingent (Russell 1989, p. 192). Another influence, more in the background, is H.G. Hubbeling's work, which combined an openness for different views with a quest for rational assessment of the merits of different opinions (Hubbeling 1963, 1971, 1987).

5. An intriguing empiricist argument for an idealist identity of mathematical ideas and the actual universe has been put forward by Barrow and Tipler (1986, p. 154f.). If the Universe is simulated with a computer programme, we can 'equate the Universe with its simulation': ‘(...) If a simulation is perfect, then those subprogrammes which are isomorphic to human beings in the general Universal Programme act the same in the simulation as humans do in the actual Universe (....). A rational subprogramme inside the Universal Programme cannot by any logically possible operation distinguish between the abstract running of the Universal Programme and a physically real, evolving Universe. Such a physically real Universe would be equivalent to the Kantian thing-in-itself. As empiricists, we are forced to dispense with such an inherently unknowable object: the Universe must be an abstract programme, or Absolute idea.'

6. The Glion report (WCC 1987b) combines 'Nature is intelligible' (p. 38) with 'Nature is ultimately mysterious. We do not know what matter (e.g. a quark) is 'in itself' '(p. 39). Clarification is needed whether or not this is the kind of persistence of mysteries Stanley Jaki claimed, and how it fits with intelligibility. Besides, it is not an element of the scientific consensus, but rather a philosophical (Kantian?) position. As such, there is a tension with the choice for critical realism.

\section{References}

Atkins, P.W.

Barbour, I.G.

Barrow, J.D., Tipler F.J.

Brout, R., et al

Craig, W.L.

Drees, W.B.

Fine, A.

Gardner, M.

Gott, J.R.
1981. The Creation, Oxford \& San Francisco: W. H. Freeman.

1974. Myths, Models, and Paradigms, New York: Harper and Row.

1986. The Anthropic Cosmological Principle, Oxford: Clarendon Press. 1980. 'Cosmogenesis and the origin of the fundamental length scale', Nuclear Physics B 170: 228-264.

1979. The Kalām Cosmological Argument, London: Macmillan. 1990. Beyond the Big Bang: Quantum Cosmologies and God, La Salle Ill.: Open Court; as thesis (University of Groningen, 1989) available in academic libraries in the Netherlands.

1984. 'The Natural Ontological Attitude', in Scientific Realism, ed. J. Leplin, Berkeley and Los Angeles: Univ. of Calif. Press. 1986. 'WAP, SAP, PAP \& FAP', The New York Review (May 8): 22-25.

1982. 'Creation of open universes from De Sitter space', Nature 295: 304-307. 
Griffin, D.R., (ed.)

Guth, A.H.
1986. Physics and the Ultimate Significance of Time: Bohm,

Prigogine, and Process Philosophy, Albany: SUNY Press.

1982. ' $10^{-35}$ seconds after the Big Bang', in The Birth of the Universe, eds. J. Audouze, J. Tran Thanh Van, Gif sur Yvette: Éditions Frontières.

1983. 'Phase Transitions in the Very Early Universe', in The Very Early Universe, eds. G.W. Gibbons, S.W. Hawking, S.T.C. Siklos, Cambridge: Cambridge Univ. Press.

Hartle, J.B., Hawking, S.W. 1983. 'Wave function of the universe', Phys.Rev.D 28: 2960-2975. Hawking, S.W. 1980. Is the End in Sight for Theoretical Physics?, Cambridge Univ. Press; reprinted in J. Boslaugh, Stephen Hawking's universe, New York: Quill/William Morrow, 1985.

1984, 'Quantum cosmology', in Relativity, Groups, and Topology II, eds. B.S. DeWitt, R. Stora, Amsterdam: North Holland. 1988. A Brief History of Time, New York: Bantam Books.

Hefner, P.J. 1984a. 'Creation: Viewed by science, affirmed by faith', in Cry of the Environment: Rebuilding the Christian Creation Tradition, eds. P. N. Joranson and K. Butigan, Santa Fe New Mexico: Bear \& Company. 1984b. 'God and Chaos: the Demiurge versus the Ungrund', Zygon 19: 469-486.

Hesse, M.

1975. 'Criteria of truth in science and theology', Religious Studies 11: $385-400$.

1981. 'Retrospect', in The Sciences and Theology in the Twentieth

Century, ed. A. R. Peacocke, Notre Dame: Univ. of Notre Dame Press.

Hubbeling, H.G. 1963. Is the Christian God-conception philosophically inferior?, Assen: Van Gorcum.

1971. Language, Logic and Criterion, Amsterdam: Born.

1987. Principles of the Philosophy of Religion, Assen: Van Gorcum.

Isham, C.J. 1988. 'Creation of the universe as a quantum process', in Physics, Philosophy, and Theology: A Common Quest for Understanding, eds.

R.J. Russell, W. R. Stoeger, G. V. Coyne, Vatican: Vatican Observatory (distr. outside Italy by Univ. of Notre Dame Press).

Jaki, S.L. 1978. The Road of Science and the Ways to God, Chicago: Univ. of Chicago Press.

1982. 'From scientific cosmology to a created universe', The Irish Astronomical Journal 15: 253-262.

Lakatos, I.
1970. 'Methodology of scientific research progammes', in Criticism and the Growth of Knowledge, eds. I. Lakatos, A. Musgrave, Cambridge: Cambridge Univ. Press (Reprinted in I. Lakatos, Philosophical Papers, Vol.I, eds. J. Worral, G. Currie, Cambridge: Cambridge Univ. Press 1978). 
Laudan, L.

Leplin, J.

Lindbeck, G.A.

Linde, A.D.

Markov, M.A.

McMullin, E.

Misner, C.W.

Mortensen, V.

Pagels, H.R.

Pannenberg, W. 1984a. 'A confutation of convergent realism', in Scientific Realism. ed. J. Leplin, Berkeley and Los Angeles: Univ. of Calif. Press.

1984b. 'Explaining the success of science: beyond epistemic realism and relativism', in Science and Reality, eds. J. T. Cushing, C. F.

Delaney, and G. M. Gutting, Notre Dame: Univ. of Notre Dame Press. 1984. 'Introduction', in Scientific Realism, ed. J. Leplin, Berkeley and Los Angeles: Univ. of Calif. Press.

1985. The Nature of Doctrine, Philadelphia: Westminster. 1983a. 'Chaotic inflation', Physics Letters B 129: 177-181. 1983b. 'The new inflationary universe scenario', in The Very Early Universe, eds. G. W. Gibbons, S.W. Hawking, S.T.C. Siklos, Cambridge: Cambridge Univ. Press.

1987a. 'Inflation and quantum cosmology', in Three Hundred Years of Gravitation, eds. S. W. Hawking, W. Israel, Cambridge: Cambridge Univ. Press.

1987b. 'Particle physics and inflationary cosmology', Physics Today 40 (Sept. 9): 61-68.

1983. 'Some remarks on the problem of the very early universe', in The Very Early Universe, eds. G.W. Gibbons, S.W. Hawking, S.T.C. Siklos, Cambridge: Cambridge Univ. Press.

1981. 'How should cosmology relate to theology?', in The Sciences and Theology in the Twentieth Century, ed. A.R. Peacocke, Notre Dame: Univ. of Notre Dame Press.

1984. 'The case for scientific realism', in Scientific Realism, ed. J. Leplin, Berkeley and Los Angeles: Univ. of Calif. Press. 1985. 'Evolution and creation', in Evolution and Creation, ed. E. McMullin, Notre Dame: Univ. of Notre Dame Press.

1986. 'Explanatory success and the truth of theory', in Scientific Inquiry in Philosophical Perspective, ed. N. Rescher, Lanham N.Y.: Univ.

Press of America.

1988. 'The shaping of scientific rationality: construction and constraint', in Construction and Constraint, ed. E. McMullin, Notre Dame: Univ. of Notre Dame Press.

1977. 'Cosmology and Theology', in Cosmology, History and Theology, eds. W.Yourgrau, A.D.Breck, New York: Plenum Press. 1987. 'The status of the science-religion dialogue', in Evolution and Creation, eds. S. Andersen, A.R. Peacocke, Aarhus: Aarhus Univ. Press. 1985. 'A cozy cosmology', The Sciences 25 (2): 34-38.

1981. 'Theological questions to scientists', in The Sciences and Theology in the Twentieth Century, ed. A.R. Peacocke, Notre Dame: Univ. of Notre Dame Press (also in Zygon 16: 65-77).

1988. 'The doctrine of creation and modern science', Zygon 23: 3-21. 
Peacocke, A.R.

Penrose, R.

Peters, T,

Plomp, H.R.

Polkinghorne, J.

Raingard, $\mathrm{P}$.

Restivo, S.

Russell, R.J.

Schwarz, J.H.

Soskice, J.M.

Swinburne, R.

Thiemann, R.F.

Torrance, T.F.

Updike, J.

Vilenkin, A.

WCC

(World Council

of Churches)

1979. Creation and the World of Science, Oxford: Clarendon.

1984. Intimations of Reality, Notre Dame: Univ. of Notre Dame Press. 1981. 'Time asymmetry and quantum gravity', in Quantum Gravity 2, eds. C.J. Isham, D.W. Sciama, R. Penrose, Oxford: Clarendon Press. 1987. 'Newton, quantum theory, and reality', in Three Hundred Years of Gravitation, eds. S.W. Hawking, W. Israel, Cambridge: Cambridge Univ. Press.

1984. 'Cosmos and Creation', Word and World 4: 372-390.

1987. 'Het heelal als hemel-en-aarde? - Kosmologie en theologie', in De plaats van aarde en mens in het heelal, M.A. Maurice, J.W.

Hovenier, H.J. Boersma, P.P. Kirschenmann en H.R. Plomp, Kampen: Kok.

1986. One World: The Interaction of Science and Theology, Princeton: Princeton Univ. Press.

1934. Le Peri tou Prosopou de Plutarque, Chartres.

1984. The Social Relations of Physics, Mysticism, and Mathematics, Dordrecht: Reidel.

1984. 'Entropy and evil', Zygon 19: 449-468.

1988. 'Contingency in physics and cosmology: a critique of the theology of Wolfhart Pannenberg', Zygon 23: 23-43.

1989. 'Cosmology, creation and contingency', in Cosmos as Creation, ed. T. Peters, Nashville: Abingdon.

1987. 'Superstring unification', in Three Hundred Years of Gravitation, eds. S.W. Hawking, W. Israel, Cambridge: Cambridge Univ. Press.

1985. Metaphor and Religious Language, Oxford: Clarendon Press.

1979. The Existence of God, Oxford: Oxford Univ. Press.

1985. Revelation and Theology, Notre Dame: Univ. of Notre Dame Press.

1981. 'Divine and contingent order', in The Sciences and Theology in the Twentieth century, ed. A. R. Peacocke, Notre Dame: Univ. of Notre Dame Press.

1986. Roger's Version, New York: Alfred Knopf.

1986. 'Boundary conditions in quantum cosmology', Physical Review D 33: 3560-3569.

1987a. Reintegrating God's creation, Church and Society Documents No. 3 (September 1987), Geneva: WCC.

1987b. Report and Background Papers: Meeting of the Working Group Glion, Switzerland, September 1987, Geneva: WCC.

1987c. Church and society newsletter, No. 8, December 1987.

Weinberg, S. 1977. The First Three Minutes, New York: Basic Books.

Zeldovich, Y.B., 1984. 'Quantum creation of a universe with nontrivial topology', Soviet Starobinsky A.A. Astronomy Letters 10: 135-137. 